\title{
KLASIFIKASI KELANCARAN KREDIT FURNITURE MENGGUNAKAN ALGORITMA K-NEAREST NEIGHBOR BERBASIS FORWARD SELECTION
}

\author{
Zainudin Sidik \\ STMIK Ichsan Gorontalo \\ Email : Zainudinsidik@gmail.com
}

\begin{abstract}
INTISARI
Salah satu bentuk dari risiko kredit adalah kredit bermasalah, yang menggambarkan suatu situasi dimana persetujuan pengembalian kredit mengalami risiko kegagalan. Dalam teknik klasifikasi terdapat beberapa algoritma yang dapat digunakan, salah satu algoritma yang sering digunakan yaitu K-NN, Penelitian ini bertujuan untuk meningkatkan kinerja algoritma KNN dengan menerapkan fitur forward selection yang digunakan untuk menyeleksi setiap fitur yang tidak terpakai saat memulai iterasi fitur, hasil dari penelitian memperlihatkan bahwa dengan menambahkan forward selection kinerja dari algoritma KNN dapat ditingkatkan. Dengan hasil nilai akurasi terbaik $94.82 \%$.
\end{abstract}

Kata kunci : Kredit, Klasifikasi, K-NN, Forward Selection

\section{A. Pendahuluan}

Kredit adalah pemberian pinjaman kepada pihak lain yang mewajibkan si peminjam untuk membayarnya kembali beserta bunganya selama jangka waktu tertentu sesuai dengan kesepakatan yang telah disepakati sebelumnya. Agar kredit yang diberikan mencapai sasaran, yaitu aman, maka analisis kredit perlu dilakukan. Melalui hasil analisis kredit, maka dapat diketahui apakah usaha nasabah feasible (layak), marketable (hasil usaha dapat dipasarkan), profitable (menguntungkan), serta dapat dilunasi tepat waktu sesuai dengan kesepakatan. (Leidiyana Henny, 2013)

Dalam melakukan penyaluran kredit, perusahaan harus siap menghadapi risiko kredit yang menyebabkan kredit tersebut menjadi bermasalah. Untuk itu, perusahaan harus melakukan perencanaan dan analisis kredit agar bisa mendeteksi kemungkinan 
terjadinya risiko kredit. Risiko kredit atau sering juga disebut dengan default risk merupakan suatu risiko akibat kegagalan atau ketidakmampuan nasabah mengembalikan jumlah pinjaman yang diperoleh dari perusahaan beserta bunganya sesuai dengan jangka waktu yang telah ditentukan atau dijadwalkan. (Yusnita Rita Tri, 2011)

Kredit bermasalah menggambarkan situasi dimana persetujuan pengembalian kredit mengalami risiko kegagalan, dan menunjukkan bahwa perusahaan akan memperoleh rugi yang potensial. Dengan munculnya kredit bermasalah, maka tingkat perputaran kas pada perusahaan akan semakin kecil. Bahkan jika kredit bermasalah sangat besar, maka perputaran kas perusahaan bisa terhenti dan seluruh dampak positif yang dapat ditimbulkan oleh penyaluran kredit tidak dapat terjadi. (Leidiyana Henny, 2013)

\section{B. Landasan Teori}

\section{a. Data Mining}

Data mining adalah proses yang menggunakan teknik statistik, matematika, kecerdasan buatan, dan machine learning untuk mengekstraksi dan mengidentifikasi informasi yang bermanfaat dan pengetahuan yang terkait dari berbagai database besar. Istilah data mining memiliki hakikat sebagai disiplin ilmu yang tujuan utamanya adalah untuk menemukan, menggali, atau menambang pengetahuan dari data atau informasi yang kita miliki. Data mining, sering juga disebut sebagai Knowledge Discovery in Database (KDD). KDD adalah kegiatan yang meliputi pengumpulan, pemakaian data, historis untuk menemukan keteraturan, pola atau hubungan dalam set data berukuran besar. (Ridwan Mujib, 2013) Tahap-tahap data mining adalah sebagai berikut:

1. Pembersihan data (data cleaning) Pembersihan data merupakan proses menghilangkan noise dan data yang tidak konsisten atau data tidak relevan.

2. Integrasi data (data integration) Integrasi data merupakan penggabungan data dari berbagai database ke dalam satu database baru.

3. Seleksi data (data selection) Data yang ada pada database sering kali tidak semuanya dipakai, oleh karena itu hanya data yang sesuai untuk dianalisis yang akan diambil dari database.

4. Transformasi data (data transformation) Data diubah atau digabung ke dalam format yang sesuai untuk diproses dalam data mining.

5. Proses mining Merupakan suatu proses utama saat metode diterapkan untuk menemukan pengetahuan berharga dan tersembunyi dari data. Beberapa metode yang dapat digunakan berdasarkan pengelompokan data mining 
6. Evaluasi pola (pattern evaluation) Untuk mengidentifikasi pola-pola menarik ke dalam knowledge based yang ditemukan.

7. Presentasi pengetahuan (knowledge presentation) Merupakan visualisasi dan penyajian pengetahuan mengenai metode yang digunakan untuk memperoleh pengetahuan yang diperoleh pengguna.

\section{b. Klasifikasi}

Klasifikasi adalah proses penemuan model (atau fungsi) yang menggambarkan dan membedakan kelas data atau konsep yang bertujuan agar bisa digunakan untuk memprediksi kelas dari objek yang label kelasnya tidak diketahui. (Leidiyana Henny, 2013) Algoritma klasifikasi yang banyak digunakan secara luas, yaitu Decision/ classification trees, Bayesian classifiers/ Nä̈ve Bayes classifiers, Neural networks, Analisa Statistik, Algoritma Genetika, Rough sets, k-nearest neighbor, Metode Rule Based, Memory based reasoning, dan Support vector machines (SVM).

Klasifikasi data terdiri dari 2 langkah proses. Pertama adalah learning (fase training), dimana algoritma klasifikasi dibuat untuk menganalisa data training lalu direpresentasikan dalam bentuk rule klasifikasi. Proses kedua adalah klasifikasi, dimana data tes digunakan untuk memperkirakan akurasi dari rule klasifikasi. (Leidiyana Henny, 2013)
Proses klasifikasi didasarkan pada empat komponen :

1. Kelas

Variabel dependen yang berupa kategorikal yang merepresentasikan 'label' yang terdapat pada objek. Contohnya: resiko penyakit jantung, resiko kredit, customer loyalty, jenis gempa.

2. Predictor

Variabel independen yang direpresentasikan oleh karakteristik (atribut) data. Contohnya: merokok, minum alkohol, tekanan darah, tabungan, aset, gaji.

3. Training dataset

Satu set data yang berisi nilai dari kedua komponen di atas yang digunakan untuk menentukan kelas yang cocok berdasarkan predictor.

4. Testing dataset

Berisi data baru yang akan diklasifikasikan oleh model yang telah dibuat dan akurasi klasifikasi dievaluasi

\section{c. Feature Selection}

Feature selection adalah sebuah proses yang biasa digunakan pada machine learning dimana sekumpulan dari features yang dimiliki data digunakan untuk pembelajaran algoritma. Subset yang baik memiliki sedikitnya dimensi angka yang paling banyak kontribusinya untuk akurasi dan nantinya akan dibuang sisa dari dimensi 
yang tidak berkepentingan. Ini merupakan langkah penting dalam tahap preprocessing. (Martin Seweel, 2007)

Algoritma seleksi fitur digunakan dengan tujuan memilih subset dari fitur yang ada di dataset sehingga tercapai tingkat akurasi maksimal dalam klasifikasi. Dua pendekatan umum untuk seleksi fitur adalah metode filter dan metode wrapper, metode filter biasanya lebih cepat dalam proses seleksi namun pendekatan wrapper memberikan kinerja yang lebih tinggi. (Matthias Reif, 2014)

\section{d. K-nearest neighbor}

Metode K-Nearest Neighbor sangat sering digunakan dalam klasifikasi. Tujuan dari algoritma ini adalah untuk mengklasifikasi objek baru berdasarkan atribut dan training samples. K-Nearest Neighbor (KNN) termasuk kelompok instance-based learning. KNN dilakukan dengan mencari kelompok $\mathrm{k}$ objek dalam data training yang paling dekat (mirip) dengan objek pada data baru atau data testing. K-NN merupakan algoritma yang menggunakan seluruh data latih untuk melakukan proses klasifikasi (complete storage). Hal ini mengakibatkan untuk data dalam jumlah yang sangat besar, proses prediksi menjadi sangat lama. (Leidiyana Henny, 2013)
Kelebihan yang dimiliki $k$-Nearest Neighbor (KNN) yaitu ketangguhan terhadap training data yang memiliki banyak noise dan efektif untuk training data yang besar. Sedangkan, kelemahan $k$-Nearest Neighbor (KNN) adalah $k$-Nearest Neighbor $(\mathrm{KNN})$ perlu menentukan nilai dari parameter k (jumlah dari tetangga terdekat), training berdasarkan jarak tidak jelas mengenai jenis jarak apa yang harus digunakan dan atribut mana yang harus digunakan untuk mendapatkan hasil terbaik, dan biaya komputasi cukup tinggi karena diperlukan perhitungan jarak dari tiap query instance pada keseluruhan training sample. (Muhammad Ilyas Sikki, 2009)

Ada banyak cara untuk mengukur jarak kedekatan antara data baru dengan data lama (data training), diantaranya euclidean distance dan manhattan distance (city block distance), yang paling sering digunakan adalah euclidean distance, yaitu: (Leidiyana Henny, 2013)

$\sqrt{\left(a_{1}-b_{1}\right)^{2}+\left(a_{2}-b_{2}\right)^{2}+\ldots+\left(a_{n}-b_{n}\right)^{2}}$

Dimana $a=a_{1}, a_{2}, \ldots, a_{n}$, dan $b=b_{1}, b_{2}, \ldots$, $b_{n}$ mewakili $n$ nilai atribut dari dua record.

Untuk mengukur jarak dari atribut yang mempunyai nilai besar, seperti atribut pendapatan, maka dilakukan normalisasi. Normalisasi bisa dilakukan dengan min-max normalization atau Z-score standardization. 
Jika data training terdiri dari atribut campuran antara numerik dan kategori, lebih baik gunakan min-max normalization.

Untuk menghitung kemiripan kasus, digunakan rumus: (Leidiyana Henny, 2013)

$$
\operatorname{Similarity}(p, q)=\frac{\sum_{i=1}^{n} f(p i, q i) X w i}{w i}
$$

Keterangan :

$\mathrm{P}=$ Kasus baru

$\mathrm{q}=$ Kasus yang ada dalam penyimpanan

$\mathrm{n}=$ Jumlah atribut dalam tiap kasus

$\mathrm{i}=$ Atribut individu antara $1 \mathrm{~s} / \mathrm{d} \mathrm{n}$

$\mathrm{f}=$ Fungsi similarity atribut $\mathrm{i}$ antara kasus $\mathrm{p}$ dan kasus q

$\mathrm{w}=$ Bobot yang diberikan pada atribut ke-i

\section{e. Forward Selection}

Forward Selection merupakan salah satu metode pemodelan (pembangunan model linier) untuk menemukan kombinasi peubah yang "terbaik" dari suatu gugus peubah. Dalam Prosedur Forward selection, sekalinya variable masuk kedalam persamaan maka tidak bisa dihilangkan. Selain itu, forward selection dapat berarti memasukkan variabel bebas yang memiliki korelasi yang paling erat dengan variabel tak bebasnya (variabel yang paling potensial untuk memiliki hubungan linier dengan Y). kemudian secara bertahap memasukkan variabel bebas yang potensial berikutnya dan nanti akan terhenti sampai tidak ada lagi variabel bebas yang potensial. (Kusuma Widya Intan, 2011)

Forward Selection merupakan pendekatan wrapper yang sering digunakan, mulai dengan fitur himpunan kosong dan interatif menambahkan fitur yang tidak di pakai. Beberapa manfaat forygrd, selection adalah mengurangi dimensionalitas feature space, sehingga mengurangi kebutuhan storage dan meningkatkan kecepatan algoritma, menghapus fitur yang tidak relevan, mengembangkan dan menambah kualitas data, mempercepat waktu running algoritma learning, mengembangkan dan menambah kualitas data, serta meningkatkan performa dan akurasi model. (L. Ladha, 2011)

\section{f. Metode Evaluasi dan Validasi}

Untuk mengukur akurasi algoritma klasifikasi, metode yang dapat digunakan antara lain cross validation, confusion matrix, dan kurva ROC (Receiver Operating Characteristic). Untuk mengembangkan aplikasi (development) berdasarkan model yang dibuat, digunakan Rapid Miner.

\section{K-fold Cross Validation}

$K$-fold cross validation merupakan salah satu metode yang digunakan untuk mengetahui rata-rata keberhasilan dari suatu sistem dengan cara melakukan perulangan dengan mengacak atribut masukan sehingga sistem tersebut teruji untuk beberapa atribut input yang acak 
K-Fold Cross Validation merupakan teknik validasi yang membagi data ke dalam $k$ bagian dan kemudian masingmasing bagian akan dilakukan proses klasifikasi. Dengan menggunakan $K$ Fold Cross Validation akan dilakukan percobaan sebanyak $k$. Tiap percobaan akan menggunakan satu data testing dan $k-1$ bagian akan menjadi data training, kemudian data testing itu akan ditukar dengan satu buah data training sehingga untuk tiap percobaan akan didapatkan data testing yang berbeda-beda. (Anto, 2015)

\section{Confusion matrix}

Metode ini menggunakan tabel matriks seperti padaTabel 1 jika data set hanya terdiri dari dua kelas, kelas yang satu dianggap sebagai positif dan yang lainnya negatif. (Leidiyana Henny, 2013)

Tabel 2.1 Confusion Matrix

\begin{tabular}{|c|l|l|}
\hline \multirow{2}{*}{$\begin{array}{c}\text { Classificat } \\
\text { ion }\end{array}$} & \multicolumn{2}{|c|}{ Predicted Class } \\
\cline { 2 - 3 } Class=Yes & $\begin{array}{l}\text { Class=Yes } \\
\text { Positive-TP) }\end{array}$ & $\begin{array}{l}\text { B (False } \\
\text { Negative-FN) }\end{array}$ \\
\hline Class=No & $\begin{array}{l}\text { C (False } \\
\text { Positive-FP) }\end{array}$ & $\begin{array}{l}\text { D (True } \\
\text { Negative-TN) }\end{array}$ \\
\hline
\end{tabular}

True positives adalah jumlah record positif yang diklasifikasikan sebagai positif, false positives adalah jumlah record negatif yang diklasifikasikan sebagai positif, false negatives adalah jumlah record positif yang diklasifikasikan sebagai negatif, true negatives adalah jumlah record negatif yang diklasifikasikan sebagai negative, kemudian masukkan data uji. Setelah data uji dimasukkan ke dalam confusion matrix, hitung nilai-nilai yang telah dimasukkan tersebut untuk dihitung jumlah sensitivity (recall), specificity, precision dan accuracy.

Sensitivity digunakan untuk membandingkan jumlah TP terhadap jumlah record yang positif sedangkan specificity adalah perbandingan jumlah $\mathrm{TN}$ terhadap jumlah record yang negatif. Untuk menghitung digunakan persamaan di bawah ini.

$$
\begin{aligned}
& \text { sensitivity }=\frac{T P}{P} \\
& \text { specificity }=\frac{T N}{N}
\end{aligned}
$$

$$
\text { precision }=\frac{\mathrm{TP}}{\mathrm{NTP}+\mathrm{FP}}
$$

$$
\begin{aligned}
\operatorname{accuracy}=\operatorname{sensitivity} \frac{\mathrm{P}}{(\mathrm{P}+\mathrm{N})} & \\
& + \text { specificity } \frac{\mathrm{N}}{(\mathrm{P}+\mathrm{N})}
\end{aligned}
$$

Keterangan:

$\mathrm{TP}=$ jumlah true positives

$\mathrm{TN}=$ jumlah true negatives

$\mathrm{P}=$ jumlah record positif

$\mathrm{N}=$ jumlah tupel negatif

$\mathrm{FP}=$ jumlah false positives 


\section{g. Kredit}

Istilah kredit berasal dari bahasa Yunani, Credere yang berarti kepercayaan (Truth atau Faith). Oleh karena itu dasar dari kredit adalah adanya kepercayaan. Seseorang atau badan usaha yang memberikan kredit (kreditur) memberikan kepercayaan bahwa penerima kredit (debitur) di masa mendatang akan sanggup memenuhi segala sesuatu yang telah disepakati kedua pihak. Kegiatan perkreditan melibatkan beberapa pihak, diantaranya adalah bank, debitur, otorita atau pemerintah, dan masyarakat. Tujuan kredit pun berbeda-beda tergantung pada pihak-pihak tersebut. (Saraswati Rosita Ayu, 2012)

Kolektibilitas pinjaman ialah penggolongan pinjaman berdasarkan keadaan pembayaran pokok atau angsuran pokok dan bunga oleh nasabah serta tingkat kemungkinan diterimanya kembali dana yang masih ditanamkan. Terdapat beberapa Kolektibilitas pinjaman sebagai berikut (Mahmoeddin As. H. Drs, 2010) :

1. Kolektibilitas Lancar

Suatu kredit dapat digolongkan lancar jika memenuhi kriteria dibawah ini.

a. Tidak terdapat tunggakan angsuran pokok, atau cerukan karena penarikan; atau

b. Terdapat tunggakan angsuran pokok, dan :

- Belum melampaui 1 (satu) bulan, bagi kredit yang ditetapkan masa angsurannya kurang dari 1 (satu) bulan; atau

- Belum melampaui 3 (tiga) bulan, bagi kredit yang ditetapkan masa angsurannya bulanan, dua bulanan, atau tiga bulanan; atau

- Belum melampaui 6 (enam) bulan, bagi kredit yang masa angsurannya ditetapkan empat bulanan atau lebih

\section{Kolektibilitas Diragukan}

Suatu kredit digolongkan diragukan apabila kredit yang bersangkutan tidak memenuhi kriteria lancar dan kurang lancar, tetapi berdasarkan penilaian dapat disimpulkan, bahwa;

a. Kredit masih dapat diselamatkan dan agunannya masih bernilai sekurangkurangnya $75 \%$ dari hutang debitur; atau

b. Kredit tidak dapat diselamatkan, tetapi agunannya masih bernilai sekurang-kurangnya $100 \%$ dari hutang debitur.

\section{Kolektibilitas Macet}

Suatu kredit digolongkan macet apabila;

a. Tidak memenuhi kriteria lancar, kurang lancar, dan diragukan; atau

b. Memenuhi kriteria diragukan tersebut pada butir 3, tetapi dalam jangka waktu 21 (dua puluh satu) bulan sejak digolongkan diragukan 
belum ada pelunasan atau usaha penyelamatan kredit; atau

c. Kredit tersebut penyelesaiannya telah diserahkan kepada pengadilan Negeri atau Badan Usaha Piutang dan Lelang Negara (BUPLN) atau telah diajukan permohonan ganti rugi kepada perusahaan asuransi kredit.

\section{Metode Penelitian}

Metode yang digunakan pada penelitain adalah K-Nearest Neighbor dengan menggunakan feature selection forward selection berikut adalah blok diagram metode penelitian :

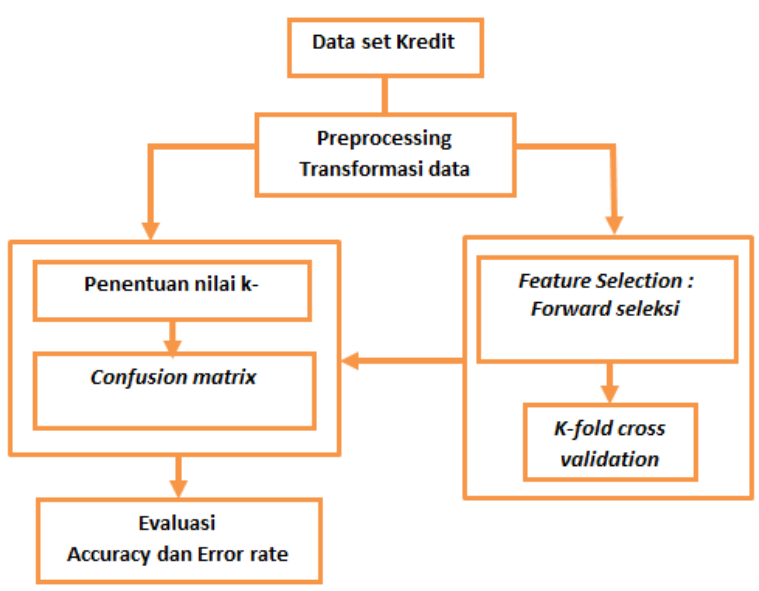

Pada penelitian ini data yang digunakan adalah dataset kredit yang didapat dari Toko Planet Furniture berupa data kredit pelanggan dengan jumlah record sebanyak 830, pada awalnya dataset tersebut memiliki jumlah atribut sebanyak 35 atribut yang selanjutnya dilakukan proses awal untuk memilih atau menyeleksi atribut-atribut yang akan berpengaruh dalam penelitian sehingga dapat meningkatkan kinerja dari algoritma, dari banyaknya atribut yang ada didapatkan 8 atribut yang berpengaruh dalam melakukan penelitian, 8 atribut terdiri dari 7 reguler atribut dan 1 spesial atribut sebagai target. Selanjutnya dilakukan proses transformasi data dari data yang bertipe nominal diubah menjadi numerik, proses ini dilakukan agar algoritma KNN dapat memproses dan menghitung nilai-nilai yang ada pada tiap atribut bertipe nominal. Langkah selanjutnya dataset diproses dengan menggunakan 2 model yaitu menggunakan algoritma KNN dan menggunakan algoritma KNN berbasis Forward selection, pada tahap ini forward selection berfungsi untuk menyeleksi atribut-atribut yang paling berpengaruh untuk selanjutnya di proses dengan menggunakan algoritma KNN. Selanjutnya untuk menguji evaluasi dan validasi algoritma digunakan confusion matrix sehingga akan didapatkan nilai akurasi dan juga error rate dari hasil eksperimen.

Berikut adalah atribut yang telah diseleksi, terdiri dari 7 reguler atribut dan 1 spesial atribut sebagai target, dapat dilihat pada tabel dibawah ini :

\begin{tabular}{|c|c|c|}
\hline Kriteria & Atribut & \multicolumn{1}{|c|}{ Penjelasan } \\
\hline $\mathrm{C} 1$ & Pekerjaan & $\begin{array}{l}\text { Status pekerjaan } \\
\text { pelanggan }\end{array}$ \\
\hline
\end{tabular}




\begin{tabular}{|c|c|c|}
\hline $\mathrm{C} 2$ & $\begin{array}{l}\text { Status } \\
\text { Perkawinan }\end{array}$ & $\begin{array}{l}\text { Status perkawinan } \\
\text { pelanggan }\end{array}$ \\
\hline C3 & Tenor & $\begin{array}{l}\text { Jangka waktu } \\
\text { kredit }\end{array}$ \\
\hline C4 & Penghasilan & $\begin{array}{l}\text { Penghasilan } \\
\text { pelanggan untuk } \\
\text { tiap bulanya }\end{array}$ \\
\hline $\mathrm{C} 5$ & $\begin{array}{l}\text { Jumlah } \\
\text { Kredit }\end{array}$ & $\begin{array}{l}\text { Total harga } \\
\text { barang yang jadi } \\
\text { kredit dengan } \\
\text { jangka waktu } \\
\text { yang dipilih } \\
\text { pelanggan }\end{array}$ \\
\hline C6 & Angsuran & $\begin{array}{l}\text { Besaran yang } \\
\text { wajib dibayar } \\
\text { oleh pelanggan } \\
\text { tiap bulanya }\end{array}$ \\
\hline C7 & Uang Muka & $\begin{array}{l}\text { Jumlah uang } \\
\text { muka yang } \\
\text { diberikan } \\
\text { pelanggan }\end{array}$ \\
\hline $\mathrm{C} 8$ & $\begin{array}{l}\text { Status } \\
\text { Kredit }\end{array}$ & $\begin{array}{l}\text { Keterangan untuk } \\
\text { status kelancaran } \\
\text { kredit }\end{array}$ \\
\hline
\end{tabular}

\section{Hasil Penelitian}

Hasil eksperimen pada penelitian ini dilakukan dengan beberapa tahap. Tahap pertama yaitu penentuan parameter $\mathrm{KNN}$, tahap kedua penentuan KNN berbasis Forward Selection. Penentuan parameter KNN dilakukan dengan cara beberapa pengujian yaitu, penentuan nilai validasi (K- fold cross validation) dan penentuan nilai ketetanggaan atau K. Hal ini dilakukan untuk mendapatkan model yang terbaik.

Berdasarkan hasil eksperimen dengan menggunakan metode $\mathrm{KNN}$ diperoleh nilai akurasi terbaik pada jarak ketetanggaan atau $\mathrm{K}$ 1, dengan menggunakan $10 \mathrm{~K}$-fold cross validation diperoleh nilai akurasi terbaik $94.49 \%$. Dari hasil eksperimen pada percobaan penetuan model K-NN dari 2 sampai dengan $10 \mathrm{~K}$-fold cross validation dapat dilihat akurasi terbaik berada pada ketetanggaan jarak terdekat K 1 .

Tabel 4.1 Rangkuman nilai akurasi terbaik yang dihasilkan ketetanggaan terdekat K 1

\begin{tabular}{|c|c|c|}
\hline K & $\begin{array}{c}\text { K-fold cross } \\
\text { validation }\end{array}$ & Akurasi \\
\hline 1 & 2 & $76.63 \%$ \\
\hline 1 & 3 & $85.90 \%$ \\
\hline 1 & 4 & $88.80 \%$ \\
\hline 1 & 5 & $91.57 \%$ \\
\hline 1 & 6 & $91.81 \%$ \\
\hline 1 & 7 & $91.57 \%$ \\
\hline 1 & 8 & $92.41 \%$ \\
\hline 1 & 9 & $94.70 \%$ \\
\hline 1 & 10 & $94.46 \%$ \\
\hline
\end{tabular}

Dari hasil tabel diatas dapat dilihat bentuk tabel confusion matrix dari nilai $\mathrm{K} 1$ dengan K-fold cross validation 9 adalah: 


\begin{tabular}{|l|c|c|c|}
\cline { 2 - 4 } \multicolumn{1}{c|}{} & $\begin{array}{c}\text { true } \\
\text { Lancar }\end{array}$ & $\begin{array}{c}\text { true } \\
\text { Tidak } \\
\text { Lancar }\end{array}$ & $\begin{array}{c}\text { class } \\
\text { precision }\end{array}$ \\
\hline $\begin{array}{l}\text { pred. } \\
\text { Lancar }\end{array}$ & 483 & 21 & $95.83 \%$ \\
\hline $\begin{array}{l}\text { pred. } \\
\text { Tidak } \\
\text { Lancar }\end{array}$ & 23 & 303 & $92.94 \%$ \\
\hline $\begin{array}{l}\text { class } \\
\text { recall }\end{array}$ & $95.45 \%$ & $93.52 \%$ & \multicolumn{1}{|c|}{} \\
\hline
\end{tabular}

Sehingga nilai Error Rate nya adalah :

Error Rate $=\frac{\text { Total Prediksi yang salah }}{\text { Total Prediksi yang benar dan salah }} \times 100 \%$

Error Rate $=\frac{23+21}{438+21+23+303} \times 100$

Error Rate $=\frac{44}{830} \times 100$

Error Rate $=\mathbf{5 , 3 0} \%$

Dapat disimpulkan bahwa perhitungan persentase tingkat akurasi pada confusion matrix dengan menggunakan $k$-Nearest Neighbor mencapai nilai accuracy sebesar 94,70 \% dengan tingkat error rate sebesar $5,30 \%$.

Sedangkan hasil eksperimen dengan menggunakan metode KNN berbasis Forward Selection diperoleh nilai akurasi terbaik yang dihasilkan ketetanggaan terdekat $\mathrm{K} 1$ dari 2 sampai dengan $10 \mathrm{~K}$-fold cross validation terdapat perbedaan nilai akurasi yang diperoleh, dengan hasil akurasi terbaik terdapat pada ketetanggaan terdekat K 1 dengan $10 \mathrm{k}$-fold cross validation sebesar $94,82 \%$.

Tabel 4.2 Rangkuman nilai akurasi terbaik yang dihasilkan ketetanggaan terdekat $\mathrm{K} 1$

\begin{tabular}{|c|c|c|}
\hline K & $\begin{array}{c}\text { K-fold cross } \\
\text { validation }\end{array}$ & Akurasi \\
\hline 1 & 2 & $78.80 \%$ \\
\hline 1 & 3 & $85.78 \%$ \\
\hline 1 & 4 & $88.31 \%$ \\
\hline 1 & 5 & $89.40 \%$ \\
\hline 1 & 6 & $92.53 \%$ \\
\hline 1 & 7 & $93.01 \%$ \\
\hline 1 & 8 & $90.96 \%$ \\
\hline 1 & 9 & $94.46 \%$ \\
\hline 1 & 10 & $94.82 \%$ \\
\hline
\end{tabular}

Forward Selection digunakan untuk menyeleksi setiap fitur yang tidak terpakai saat memulai iterasi fitur. Pada proses ini, nilai akurasi terbaik di peroleh $94.82 \%$. dengan atribut weight yang dihasilkan adalah :

Tabel 4.3 Atribut Weight KNN berbasis Forward Selection dari nilai K 1 dengan Kfold cross validation 10. 


\begin{tabular}{|l|c|}
\hline \multicolumn{1}{|c|}{ Atribut } & Weight \\
\hline Status Perkawinan & 1 \\
\hline Pekerjaan & 1 \\
\hline Penghasilan & 1 \\
\hline Jumlah Kredit & 1 \\
\hline Angsuran & 0 \\
\hline Tenor & 1 \\
\hline Uang Muka & 0 \\
\hline
\end{tabular}

Dari hasil tabel diatas dapat dilihat bentuk tabel confusion matrix dari nilai $\mathrm{K} 1$ dengan K-fold cross validation 10 adalah:

\begin{tabular}{|l|c|c|c|}
\cline { 2 - 4 } \multicolumn{1}{c|}{} & $\begin{array}{c}\text { true } \\
\text { Lancar }\end{array}$ & $\begin{array}{c}\text { true } \\
\text { Tidak } \\
\text { Lancar }\end{array}$ & $\begin{array}{c}\text { class } \\
\text { precision }\end{array}$ \\
\hline $\begin{array}{l}\text { pred. } \\
\text { Lancar }\end{array}$ & 473 & 10 & $97.93 \%$ \\
\hline $\begin{array}{l}\text { pred. } \\
\text { Tidak } \\
\text { Lancar }\end{array}$ & 33 & 314 & $90.49 \%$ \\
\hline $\begin{array}{l}\text { class } \\
\text { recall }\end{array}$ & $93.48 \%$ & $96.91 \%$ & \multicolumn{1}{|c}{} \\
\hline
\end{tabular}

Sehingga nilai Error Rate nya adalah :

$$
\text { Error Rate }=\frac{\text { Total Prediksi yang salah }}{\text { Total Prediksi yang benar dan salah }} \times 100 \%
$$

Error Rate $=\frac{33+10}{438+21+23+303} \times 100$

Error Rate $=\frac{43}{830} \times 100$
Dapat disimpulkan bahwa perhitungan persentase tingkat akurasi pada confusion matrix dengan menggunakan $k$-Nearest Neighbor mencapai nilai accuracy sebesar 94,82\% dengan tingkat error rate sebesar $5,18 \%$.

\section{E. Kesimpulan}

Berdasarkan hasil pengujian data pelanggan kredit yang diklasifikasikan dengan penggunaan seleksi fitur forward selection dapat menghasilkan tingkat akurasi yang lebih baik dari algoritma KNN. Hal ini dapat dilihat dari peningkatan akurasi yang telah dihasilkan. Algoritma dengan tambahan seleksi fitur forward selection menghasilkan tingkat akurasi $94.82 \%$. akurasi yang dihasilkan dalam penelitian ini telah berhasil melebihi hasil akurasi dari peneliti sebelumnya yang mampu menghasilkan akurasi sebesar 90,00\% dengan menggunakan metode Decission Tree (C4.5).

\section{DAFTAR PUSTAKA}

Anggri Nastiti, “Analisis faktor-faktor yang mempengaruhi tingkat pengambilan kredit pengusaha kecil pada program kemitraan". Universitas Brawijaya. 2012. 
Anto, "Prediksi time series harga komoditi kakao dan jagung dengan Algoritma Backpropagation Neural Network berbasis Forward Selection", M.TI thesis, Universitas Dian Nuswantoro, Semarang, 2015.

Dwi Poetry Zakiyah, D. Sanrego Yulizar, "Pengaruh Variabel Makro Dan Mikro Terhadap Npl Perbankan Konvensional Dan Npf Perbankan Syariah", TAZKIA Islamic Finance \& Business Review, Vol. 6, No.2, Agustus - Desember 2011

Fareed Akthar dan Caroline Hahne "RapidMiner 5 Operator Reference". Rapid-I GmbH. All rights reserved (C) 2012

Hasan Maryam, "Prediksi Tingkat Kelancaran Pembayaran Kredit Bank Menggunakan Algoritma Naïve Bayes Berbasis Forward Selection", Thesis MTI, Universitas Dian Nuswantoro. 2014

Hidayatullah Ahmad Fathan, "Analisis

Sentimen Dan Klasifikasi Kategori Terhadap Tokoh Publik Pada Data Twitter Menggunakan Naive Bayes Classifier", Thesis Ilmu Komputer, Universitas Gajah Mada, Yogyakarta, 2014

Kusuma Widya Intan, Abadi M. A, Aplikasi Model Backpropagation Neural Network Untuk Perkiraan Produksi Tebu Pada PT. Perkebunan
Nusantara IX, Universitas Negeri yogyakarta. 2011

L. Ladha, T. Deepa, "Feature Selection Methods And Algorithms", International Journal on Computer Science and Engineering (IJCSE), ISSN : 0975-3397 Vol. 3 No. 5 May 2011.

Leidiyana Henny, "Penerapan Algoritma $K$ Nearest Neighbor Untuk Penentuan Resiko Kredit Kepemilikan Kendaraan Bemotor", Thesis MI, STMIK Nusa Mandiri. 2013.

Mahmoeddin As. H. Drs, "Melacak Kredit Bermasalah", Jakarta, Pustaka Sinar Harapan, 2010, hal. (2, 12-14, 47-48) Martin Seweel, "Feature Selection", 2007 Matthias Reif, Faisal Shahait,"Efficient Feature Size Reduction Via Predicitive Forward Selection". Pattern Recognition ,47, 1664-1673. 2014.

Muhammad Agus Salman, "Pemanfaatan Metode Klasifikasi untuk Prediksi Keberhasilan Siswa SMA Diterima Perguruan Tinggi (Studi Kasus : SMA N 1 Ponorogo)”, Thesis Ilmu Komputer, Universitas Gajah Mada, Yogyakarta, 2015

Muhammad Ilyas Sikki, M. "Pengenalan Wajah Menggunakan K-Nearest Neighbour Dengan Praproses Transformasi Wavelet", Jurnal Paradigma Vol X. No. 2, Desember 2009. 
Mr.Ram Babu, Mr.A.Rama Satish.” Improved of K-Nearest Neighbor Techniques in Credit Scoring”, International Journal For Development of Computer Science \& Technology, Volumn-1, Issue-2, FebMarch-2013.

N. Suguna, and Dr. K. Thanushkodi, “An Improved k-Nearest Neighbor Classification Using Genetic Algorithm", IJCSI International Journal of Computer Science Issues, Vol. 7, Issue 4, No 2, July 2010.

Prasetyo Eko, "Nearest Neighbor Sistem

Berbasis Fuzzy Materi 4", Universitas

Muhammadiyah Gresik. 2012

Raden Sofian Bahri, Irfan Maliki, "Perbandingan Algoritma Template Matching dan Feature Extraction Pada Optical Character Recognition". Jurnal Komputer dan Informatika (KOMPUTA), Edisi I Volume 1, Maret 2012.

Ridwan Mujib, Suyono Hadi, dan Sarosa M
Evaluasi Kinerja Akademik

Mahasiswa Menggunakan Naive Bayes Classifier", Jurnal EECCIS Vol.7, No. 1, Juni 2013

Saraswati Rosita Ayu, "Peranan Analisis Laporan Keuangan, Penilaian Prinsip 5C Calon Debitur dan Pengawas Kredit Terhadap Efektifitas Pembeeriann kredit”. Jurnal Nominal, Vol. 1, No 1, Tahun 2012

Siami M. Ikbal, "Sistem Question Answering Fiqih Berbasis Ontologi Dengan Klasifikasi Pertanyaan Menggunakan Support Vector Machine", Thesis Ilmu Komputer, Universitas Gajah Mada, Yogyakarta, 2015 .

Yusnita Rita Tri , "Pengaruh Kredit Bermasalah Terhadap Perputaran Kas Dan Dampaknya Terhadap Likuiditas (Studi Kasus Pada PT. BPR Mitra Kopjaya Mandiri Manonjaya Tasikmalaya)", Jurnal Akuntansi Vol. 6, no 2, July-Des 2011.

"Penerapan Data Mining Untuk 